\title{
Editorial
}

\section{¿Necesita Euskadi una renta básica universal?}

Como consecuencia de la actual crisis económica, política y social, se ha reavivado en los últimos años el debate sobre la renta básica universal (RBU). Planteada por algunos como una herramienta casi mágica para eliminar la pobreza y responder a la crisis de la sociedad salarial, el debate sobre la RBU esconde, sin embargo, una serie de mitos, mantras y medias verdades que dificultan un debate objetivo sobre sus verdaderas ventajas y desventajas. El objetivo de este editorial es subrayar algunos de esos mitos y medias verdades, y responder a la pregunta de si Euskadi necesita, realmente, una renta básica universal. Para ello, es necesario determinar en qué medida la propuesta de RBU sería más eficaz que las actuales rentas garantizadas a la hora de erradicar la pobreza o de enfrentarse a la crisis del empleo.

El argumento central de este texto es el de que, para responder a la necesidad de disociar el empleo de la supervivencia - un objetivo a todas luces necesario-, la RBU no es necesariamente más útil o funcional que un sistema de renta garantizada adecuadamente diseñado: la renta de garantía de ingresos (RGI), desde hace años, permite desvincular el empleo de la supervivencia, ofreciendo un ingreso mínimo a todos aquellos que no pueden trabajar, independientemente de su historial contributivo. Tampoco la RBU es, necesariamente, más eficaz que la RGI a la hora de reducir la pobreza: dependerá de las cuantías y condiciones de acceso que se establezcan para cada prestación. De hecho, como ha señalado José Antonio Noguera (2015), las diferencias entre rentas mínimas garantizadas y renta básica universal se evaporan fácilmente dependiendo de cómo se implemente, en la práctica, cada una de estas políticas.

\section{Trucos contables}

Los trabajos de simulación del impacto y el coste de la RBU que hasta la fecha se han realizado en nuestro entorno -incluyendo el que llevaron a cabo en 2014 Arcarons, Raventós y Torrens para Gipuzkoa (2014) - parten de un error metodológico que invalida algunas de sus conclusiones y hurta el debate real que las instituciones y la ciudadanía deben afrontar en relación con el modelo de garantía de ingresos. En efecto, esos trabajos de simulación comparan la situación ex ante (es decir, la actual) con la que se produciría ex post (una vez aplicada su propuesta de RBU). Pero no tienen en cuenta, a la hora de calcular la situación de partida, el efecto que prestaciones como la renta de garantía de ingresos (RGI) tienen en la situación económica de los grupos más desfavorecidos de nuestra sociedad.

De ese error metodológico se derivan varias conclusiones erróneas. Se concluye, por una parte, que con la introducción de la RBU el $10 \%$ más pobre de la población pasaría de aportar al fisco el $0,5 \%$ de sus ingresos a recibir una aportación neta equivalente al $200 \%$ de sus ingresos iniciales, es decir, a multiplicar por tres sus ingresos actuales. Parecidos cálculos se plantean para Cataluña (Arcarons, Raventós y Torrens, 2016) o para el conjunto del Estado (Arcarons et al., 2014).

La realidad, sin embargo, no es ésa, al menos en Euskadi: si se aplicara aquí esa propuesta, una persona perceptora de la RGI sin ingresos propios apenas ganaría 40 euros mensuales gracias a la introducción de la renta básica universal y, de hecho, perdería del orden de 3.000 euros anuales si, además de la RGI, percibía anteriormente la prestación complementaria de vivienda, ya que la propuesta de RBU implica la desaparición de las prestaciones selectivas de inferior cuantía (ayudas a la vivienda, ayudas familiares, becas, deducciones fiscales) que en la actualidad abonan distintos sistemas (servicios sociales, educación, Seguridad Social, fiscalidad). El efecto del cambio sería aún peor para un trabajador de bajo salario cubierto por la RGI: en la actualidad (datos 2015), con los estímulos al empleo, un salario de 500 euros se complementa, si se cumplen las demás condiciones 
de acceso, con una RGI de 482 euros, lo que supone unos ingresos anuales de casi 12.000 euros, no sujetos a impuestos. Con la RBU propuesta para Gipuzkoa, aplicando un tipo único del $49 \%$, esta persona perdería casi 1.000 euros anuales, a lo que habría que sumar, de acuerdo con la propuesta, los 3.000 euros de prestación complementaria de vivienda a los que la percepción de la RGI, en su modalidad de estímulos al empleo, da derecho.

No es, por tanto, cierto, como señalan los autores de esta propuesta, que el $75 \%$ menos rico de la sociedad guipuzcoana se vería beneficiado por el cambio que proponen: algunas de las personas más pobres de nuestra sociedad saldrían perdiendo, y otras - por ejemplo, las unidades perceptoras de la RGI con más de dos miembros- saldrían ganando, pero en mucha menor medida de lo que los autores de esos estudios de simulación sugieren. A esa misma conclusión llegan las simulaciones, más honestas, realizadas, por ejemplo, en Francia (De Basquiat, 2016): en ese caso, con la RBU propuesta, los ingresos del $10 \%$ más pobre de la población se incrementarían por término medio en un relativamente modesto $18 \%$, y la nómina de perdedores se extendería a lo largo de toda la escala de rentas, si bien se concentraría especialmente a partir de ingresos superiores a los 1.500 euros mensuales.

El error no es baladí. En primer lugar, olvida que, de acuerdo con la Encuesta de Pobreza y Desigualdades Sociales (EPDS) [Gobierno Vasco, 2014], el $41 \%$ de los ingresos de las personas que viven en Euskadi en situación de pobreza provienen precisamente del sistema vasco de garantía de ingresos. Por tanto, no es que aporten al sistema el $0,5 \%$ de su renta, sino que reciben una aportación equivalente al $211 \%$ de sus ingresos iniciales, gracias a la RGI y a los demás sistemas de protección social. Y, sobre todo, este "truco contable" evita enfocar la discusión política en sus justos términos. Los promotores de la renta básica plantean el debate entre dos alternativas: por una parte, su propuesta de renta básica incondicional y universal; y por otra, un sistema en el que -más allá de la protección social contributiva y otras ayudas menores- las personas en edad de trabajar no pueden acceder a ningún sistema de garantía de ingresos. El debate real se centra, sin embargo, entre la propuesta de renta básica universal e incondicional, por un lado, y el actual sistema de renta garantizada, condicional y selectivo, por otro (un sistema que, pese a las críticas que recibe desde los dos extremos del arco parlamentario vasco, reduce la extensión de la pobreza en un $40 \%$ y su intensidad en casi un $80 \%$ ).

\section{Mitos y mantras}

Más allá de este "error contable" en la estimación del impacto de la RBU, la defensa que habitualmente se hace de esta propuesta se basa en una serie de mitos y mantras que subrayan los efectos positivos de la reforma y minimizan, u ocultan, sus efectos adversos.
Se exagera, por ejemplo, cuando se señala que la RBU eliminará, de un plumazo, la pobreza. Sin duda, una prestación universal, individual e incondicional de suficiente cuantía (asociada además a un incremento de la presión fiscal para los grupos más favorecidos) reducirá la desigualdad y las tasas de pobreza. Puede incluso garantizar a toda la población cubierta por el sistema ingresos superiores al umbral de pobreza previo al momento de su introducción. Pero mientras la pobreza se siga considerando un fenómeno relativo, definido en función del ingreso mediano de la sociedad en un momento dado, será difícil que una parte de la población no se encuentre por debajo de un porcentaje (ya sea el $40 \%$, ya sea el $60 \%$ ) de ese umbral. En ese sentido, dependiendo de la evolución de los ingresos del resto de la sociedad, no es posible determinar en qué medida quienes únicamente perciban la RBU estarían por encima o por debajo del umbral de pobreza (de hecho, la propuesta planteada en Francia -De Basquiat (2016) - para introducir una RBU reconoce que la nueva prestación no permitiría a sus beneficiarios salir de la pobreza, salvo que se complemente con algún otro ingreso).

También resulta obvio que vivirían en situación de pobreza todas aquellas personas que - por ejemplo, por no residir legalmente en el país- no pudieran acceder ni a un puesto de trabajo, ni a esta prestación, ni a ninguna otra prestación asistencial. En ese sentido, cuando una parte importante de la ciudadanía rechaza la concesión de ayudas económicas condicionales a las personas extranjeras asentadas entre nosotros, la determinación de los criterios de acceso a la RBU constituye un elemento esencial, no siempre suficientemente aclarado.

En todo caso, no es cierto que la RBU resulte necesariamente más eficaz que las actuales rentas garantizadas para reducir la pobreza: dependerá de las cuantías y condiciones de acceso de cada propuesta (y, de hecho, habría que recordar que al menos 15 de los 28 países de la UE, incluyendo la CAPV, registran en la actualidad, sin RBU, tasas de pobreza severa inferiores al $5 \%$ de la población).

El propio carácter universal y no selectivo de la RBU es, en realidad, un mito: cuando se afirma que la RBU implica conceder una asignación económica a todas las personas, independientemente de su renta, hay también que recordar que, para ello, se establecería - al menos en la mayor parte de las propuestas analizadas - un tipo único en el IRPF cercano al $50 \%$ (en los trabajos de Arcarons et al. consultados, el tipo propuesto oscila entre el $40 \%$ y el $49 \%)$. De esa forma, aplicando el tipo del $49 \%$ a la realidad guipuzcoana, una persona soltera con un salario bruto de 28.000 euros anuales (unos 1.500 euros netos mensuales) recibiría efectivamente una prestación incondicional cercana a los 8.000 euros anuales, pero pagaría, al mismo tiempo, un IRPF cercano a los 14.000 euros por sus ingresos salariales, frente a unos 5.000 en la actualidad. La nueva prestación sería, por tanto, absorbida por los nuevos tipos impositivos, y la presión fiscal real 
de esta persona pasaría del actual $17 \%$ al $20 \%$, reduciendo sus ingresos en un $4 \%$ en relación con la situación actual. El deterioro sería mayor en caso de beneficiarse actualmente, por ejemplo, de una ayuda al alquiler o de una deducción fiscal. En términos netos, por tanto, la prestación universal no deja de ser regresiva y, a la postre, selectiva.

La cuestión relevante no es, en definitiva, si el sistema es o no selectivo, porque en realidad ambos lo son: lo relevante es el impacto combinado de la cuantía garantizada y el tipo único que se establezca, que es lo que determina quién realiza una aportación neta al sistema, quién obtiene una prestación neta, y quién gana o pierde, y cuánto, con el cambio.

Por otra parte, si bien la RBU se plantea como una solución a la famosa trampa de la pobreza (en teoría, las personas que perciben rentas garantizadas no acceden al mercado laboral, porque ello apenas les supone un incremento de sus ingresos, pese al esfuerzo adicional que todo empleo requiere), se olvida también, al plantear las bondades comparativas de la RBU, que los sistemas actuales de rentas garantizadas ya contemplan este tipo de medidas, al menos cuando se diseñan en la lógica del making work pay. De hecho, desde ese punto de vista, la propuesta de Arcarons et al. se diferencia de los actuales modelos de rentas mínimas únicamente en la tasa de imposición aplicada a las ganancias salariales: $38 \%$ en el actual modelo francés, por ejemplo, $49 \%$ en el modelo de RBU planteado para Cataluña o para el Estado español. No se plantea, sin embargo, en qué medida una imposición del $49 \%$ a cualquier salario, incluyendo los más bajos, puede -habiéndose asegurado previamente un ingreso incondicional-desincentivar el acceso al empleo o, al menos, al empleo no sumergido.

Tampoco se tiene en cuenta el efecto inflacionario que tendría en el conjunto de la economía el inevitable incremento que, como se señala más adelante, experimentarían los costes salariales en los puestos de trabajo más duros y peor pagados.

Hay otros tres mitos, o medias verdades, sobre los que se asienta la defensa de la RBU. Se señalan a continuación de forma muy resumida:

- Los promotores de la RBU plantean a menudo que, al ser una prestación individual, permitiría a las mujeres una mayor independencia en relación con los hombres, puesto que no estarían obligadas a mantener una relación no deseada por carecer de medios para la independización. A veces se olvida, sin embargo, en qué medida una renta incondicional implicaría el retorno de muchas mujeres - por propia voluntad o tras "negociación" con su pareja- a las actividades domésticas y de cuidado, reforzando de nuevo los roles tradicionales de género. En efecto, la opción de muchas personas que conviven con otras que perciben un salario medio o alto será, sin duda, la inactividad profesional y el regreso a lo que antes se conocía como "sus labores". Aunque libremente elegida (cabe pensar), la renta básica incondicional se convertiría así, en gran medida, en el salario de las amas de casa.

- También tiene mucho de mito la idea de que la renta básica supondrá una mejora en términos de estatus y de integración social, y de que su concesión terminaría con el estigma que se asocia actualmente a los perceptores de las rentas garantizadas. Si bien es cierto que la concesión automática de la prestación y su carácter incondicional evitarían situaciones y trámites intrínsecamente estigmatizantes (además de complejos y caros), la divisoria entre quienes no trabajan y perciben una renta neta y quienes trabajan y hacen una aportación neta en forma de impuestos no dejaría de ser también intrínsecamente estigmatizante.

- Por último, también cabe considerar como un mito la vinculación que se hace entre la necesidad de introducir la renta básica incondicional y el pretendido fin del empleo. En efecto, más allá de las incertidumbres actuales sobre las consecuencias de la robotización y los cambios en la demanda de puestos de trabajo, no hay ninguna razón para pensar que una renta básica incondicional puede responder a ese nuevo escenario mejor que las rentas garantizadas (especialmente si éstas se diseñaran en una clave diferente a la actual). Si se trata de adaptarse a una sociedad con menores niveles de empleo, bastaría con garantizar un ingreso digno y seguro a toda persona que no pueda trabajar y no, necesariamente, a toda persona que opta libremente por no trabajar.

\section{De qué estamos hablando}

El hecho de que los defensores de la RBU recurran a este tipo de trucos, mitos y mantras no implica, en todo caso, que la introducción de una renta básica individual e incondicional no fuera a tener efectos positivos en el ámbito vasco. Entre ellos, cabría destacar tres:

- Una más que notable simplificación de la gestión administrativa de las actuales rentas garantizadas, en la medida en que no sería necesario acreditar ni la disponibilidad para el trabajo, ni la realización de actividades para la inclusión, ni la carencia de otras fuentes de ingresos. Si bien es cierto que una parte de los problemas administrativos relativos a la valoración de ingresos y patrimonio se trasladarían al ámbito fiscal, parece claro que el carácter individual, incondicional y no selectivo de esta prestación evitaría el cortejo de intromisiones en la vida privada que los modelos selectivos de rentas garantizadas requieren en la actualidad, permitiendo una gestión mucho más ágil, simple y normalizada. En todo caso, también es cierto que algunos de los problemas actuales de las rentas garantizadas -como las dificultades 
para la identificación individual de las personas beneficiarias o la certificación de la residencia efectiva en Euskadi- se seguirían produciendo en el nuevo sistema.

- La reducción del problema del no recurso o non take up, es decir, el no acceso a la prestación de personas en situación de necesidad. Cabe recordar, en este sentido, que en la actualidad el $27 \%$ de las personas potencialmente demandantes de la RGI no acceden a esta prestación, bien por no cumplir los requisitos de acceso, bien por no haber solicitado la prestación. En todo caso, si bien es cierto que accederían automáticamente a la prestación todas las personas que cumplieran los requisitos de acceso, se mantendrían, como antes se ha dicho, sectores potencialmente demandantes - 0 , al menos, en situación de necesidad-que no accederían a la prestación por no cumplir los requisitos de acceso (especialmente en lo que se refiere a la residencia en el territorio).

- El incremento de las cuantías y la individualización de la prestación también tendría un efecto positivo en la mejora de la situación de una parte significativa de las personas que actualmente perciben la RGI o que están en situación de pobreza (aunque no de todas, como antes se ha señalado, y no en la medida que los cálculos de sus promotores sugieren). Parece claro, en todo caso, que el modelo planteado por los defensores de la RBU implica un esfuerzo redistributivo mayor, y una mayor capacidad de reducción de la extensión y la intensidad de la pobreza, desvinculándose además la cuantía de la prestación de los salarios más bajos (en la actualidad, el nivel salarial de los puestos menos cualificados actúa como techo de cristal para estas prestaciones, que, para no desincentivar el acceso al empleo, no pueden superar esos niveles salariales). No debe olvidarse, sin embargo, que, como en todo ejercicio de redistribución, esta mejora de la capacidad de reducción de la pobreza implica pérdidas y ganancias. Los perdedores -ese $25 \%$ más rico de la población- está más presente en la sociedad de lo que se tiende a pensar: de acuerdo con la EPDS, en 2014 el ingreso medio neto per cápita de los hogares situados en las tres decilas superiores de la distribución de la renta era, en Euskadi, de 2.300 euros al mes.

De hecho, como hemos visto antes, con un tipo del $49 \%$, la nómina de perdedores sería mucho más generalizada, iniciándose las pérdidas ya en los niveles salariales medios o incluso bajos (en el mismo sentido, la simulación francesa antes señalada -De Basquiat (2016) - identifica ganadores y perdedores de la reforma a lo largo de toda la distribución de ingresos, si bien lógicamente los perdedores se concentran entre la población de ingresos superiores a 1.500 euros, mientras que los ganadores están fundamentalmente, pero no sólo- entre quienes perciben ingresos inferiores a esa cantidad).

En todo caso, los tres beneficios que se acaban de señalar tienen poco que ver con el carácter incondicional de la RBU y podrían, de hecho, alcanzarse mediante la mejora del actual sistema de rentas garantizadas. Sería, para ello, necesario avanzar hacia un modelo de garantía de ingresos más normalizado, más ágil y de gestión más sencilla, menos condicional y mejor articulado con el resto de las políticas de empleo y de protección social.

El principal efecto que la introducción de la RBU tendría no se refiere, por tanto, ni a la simplificación de los trámites administrativos, ni mucho menos a la reducción de la pobreza y la mejora de la situación de la población más desfavorecida. El principal cambio que traería consigo la RBU tiene que ver, en realidad, con la posibilidad de optar voluntariamente por no trabajar; es decir, con la posibilidad de percibir una renta, aunque sea pequeña, sin necesidad de trabajar o de demostrar la imposibilidad de hacerlo. La incondicionalidad es la verdadera piedra angular, y el verdadero cambio, de la RBU. Y lo es porque, como sostienen los promotores de la medida (Raventós y Casassas, 2003), otorga a los trabajadores un poder de negociación muy superior al actual, en la medida en que nadie estaría obligado a aceptar, por necesidad, un empleo desagradable o mal pagado. Independientemente de la valoración que pueda hacerse de ese cambio en términos normativos o filosóficos, no cabe duda de que -frente al carácter condicional de las actuales rentas garantizadas-, dotaría a todas las personas de una mayor capacidad de elección y supondría un cambio radical en la correlación de fuerzas entre el trabajo y el capital.

Así pues, a la pregunta que abre este texto — ¿necesita Euskadi una renta básica universal?_habría que contestar: depende. En efecto, la respuesta a esa pregunta dependerá de los objetivos y prioridades que la propia sociedad vasca se quiera marcar. Si su objetivo es el de maximizar la libertad individual y dotar de un mayor poder de negociación a los trabajadores menos cualificados, Euskadi necesita efectivamente una renta básica universal. $\mathrm{Si}$, por el contrario, lo que la sociedad busca es un modelo de garantía de ingresos económica y socialmente sostenible, que desvincule el empleo de la supervivencia, que reduzca la pobreza y proteja a todas las personas que, por motivos ajenos a su voluntad, no disponen de los recursos económicos necesarios para hacer frente a sus necesidades, la extensión y mejora del actual modelo de garantía de ingresos - articulado en torno a la RGI-sería, sin duda, una vía más sencilla, más discreta y más barata

En definitiva, la contraposición radical que a menudo se plantea entre renta básica y renta garantizada es más aparente que real, al menos en muchos de sus elementos. Por ello, frente a la propuesta de abolir el actual sistema de garantía de ingresos para introducir una RBU más cara y con menor apoyo social, no necesariamente más eficaz o más justa, resultaría más útil -siguiendo, por ejemplo, las propuestas de Fernández et al. (2015) -avanzar por caminos menos maximalistas y, en definitiva, más transitables (Noguera, 2014). 


\section{Bibliografía}

ARCARONS, J.; RAVENTÓS, D.; y TORRENS, L. (2016): “La renda bàsica incondicional: una proposta racional per al segle xxi”, Nota d'Economia, no 103, págs. 173-193 ['http://economia.gencat. cat/web/.content/70_economia_catalana/ arxius/publicacions_periodiques/nota_d_ economia/ne_103/NE_103_c12.pdf〉].

-(2014): “Una propuesta [de] financiación de una renta básica en Gipuzkoa" (comunicación), en XIII Simposio Renta Básica, Donostia, febrero 2014 [<http://www.nod050.org/redrentabasica/ descargas/13simposiguip.pptx>].

ARCARONS, J. et al. (2014) “Un modelo de financiación de la Renta Básica para el conjunto del Reino de España: sí, se puede y es racional", Sin Permiso, 7-12-2014 [/http://www.sinpermiso. info/textos/un-modelo-de-financiacin-de-larenta-bsica-para-el-conjunto-del-reino-deespaa-s-se-puede-y-es〉].

DE BASQUIAT, M. (2016): Le Revenu d'Existence: des principes, une cible et un chemin, Association pour l'Instauration d'un Revenu d'Existence [rhttp://www.ofce.sciences-po.fr/pdf/ seminaires/sem20161013/11.pdf>].

FERNÁNDEZ, G. (coord.) (2015): Hacia un sistema más inclusivo de garantía de rentas en España: diferentes alternativas de desarrollo, Madrid, Fundación Foessa; Cáritas Española Editores [rhttp://www.foessa.es/publicaciones_ download.aspx?Id=5201)].

GOBIERNO VASCO. DEPARTAMENTO DE EMPLEO Y POLÍTICAS SOCIALES. ÓRGANO ESTADÍSTICO (2014): Encuesta de Pobreza y Necesidades Sociales, Vitoria-Gasteiz: Gobierno Vasco, Tabla 13 [khttp://www.euskadi.eus/webo1-szenple/ es/contenidos/informacion/epds_oe informacion/es_def/index.shtmls].

NOGUERA, J. A. (2015): “¿Renta básica universal vs. renta garantizada? Algunos mitos y leyendas", Agenda Pública, 28-7-2015 [khttp:// agendapublica.es/renta-basica-universal-vsrenta-garantizada-algunos-mitos-y-leyendas/>].

- (2014): “La Renta Básica: el camino transitable”. El Diario.es, 4-12-14 [/http://www.eldiario.es/ agendapublica/impacto_social/Renta-Basicacamino-transitable_0_334916806.html >].

RAVENTÓS, D.; y CASASSAS, D. (2003): “La Renta Básica y el poder de negociación de "los que viven con permiso de otros"', Revista Internacional de Sociología, $n^{\circ} 34$, págs. 187-201 [<https://doi. org/10.3989/ris.2003.i34.291>]. 